\title{
Will My Tibial Fracture Heal? Predicting Nonunion at the Time of Definitive Fixation Based on Commonly Available Variables
}

\author{
Kevin O'Halloran MD, Max Coale BA, Timothy Costales BS, \\ Timothy Zerhusen Jr BS, Renan C. Castillo PhD, Jason W. Nascone MD, \\ Robert V. O'Toole MD
}

Published online: 28 April 2016

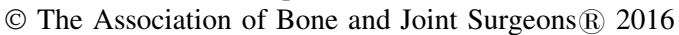

\begin{abstract}
Background Accurate prediction of tibial nonunions has eluded researchers. Reliably predicting tibial nonunions at the time of fixation could change management strategies and stimulate further research.

Questions/purposes We asked (1) whether data from medical records, fracture characteristics, and radiographs obtained at the time of fixation would identify features predictive of tibial fracture nonunion; and (2) whether this information could be used to create a model to assess the
\end{abstract}

One of the authors (JWN) received funding from AO North America. All ICMJE Conflict of Interest Forms for authors and Clinical Orthopaedics and Related Research ${ }^{\mathbb{R}}$ editors and board members are on file with the publication and can be viewed on request. Clinical Orthopaedics and Related Research ${ }^{\circledR}$ neither advocates nor endorses the use of any treatment, drug, or device. Readers are encouraged to always seek additional information, including FDA approval status, of any drug or device before clinical use.

Each author certifies that his institution approved the human protocol for this investigation, that all investigations were conducted in conformity with ethical principles of research, and that informed consent for participation in the study was obtained.

This work was performed at R Adams Cowley Shock Trauma Center, Department of Orthopaedics, University of Maryland School of Medicine, Baltimore, MD, USA.

K. O'Halloran

Regions Hospital/University of Minnesota, St Paul, MN, USA

M. Coale, T. Costales, T. Zerhusen Jr, J. W. Nascone,

R. V. O'Toole $(\bowtie)$

R Adams Cowley Shock Trauma Center, Department of Orthopaedics, University of Maryland School of Medicine, 2200

South Greene Street, SuiteT3R62, Baltimore, MD 21201, USA

e-mail:rvo3@yahoo.com

R. C. Castillo

Johns Hopkins Bloomberg School of Public Health, Baltimore, MD, USA chance of nonunion at the time of intramedullary (IM) nail fixation of the tibia.

Methods We retrospectively reviewed all tibial shaft fractures treated at our center from 2007 to 2014. We conducted a literature review and collected data on 35 factors theorized to contribute to delayed bone healing. Patients were followed to fracture healing or surgery for nonunion. Patients with planned prophylactic nonunion surgery were excluded because their nonunions were anticipated and our focus was on unanticipated nonunions. Our cohort consisted of 382 patients treated with IM nails for tibial shaft fractures (nonunion, 56; healed, 326). Bivariate and multivariate regression techniques and stepwise modeling approaches examined the relationship between variables available at definitive fixation. Factors were included in our model if they were identified as having a modest to large effect size (odds ratio $>2$ ) at the $\mathrm{p}<0.05$ level.

Results A multiple variable logistic regression model was developed, including seven factors $(\mathrm{p}<0.05$; odds ratio $>$ 2.0). With these factors, we created the Nonunion Risk Determination (NURD) score. The NURD score assigns 5 points for flaps, 4 points for compartment syndrome, 3 points for chronic condition(s), 2 points for open fractures, 1 point for male gender, and 1 point per grade of American Society of Anesthesiologists Physical Status and percent cortical contact. One point each is subtracted for spiral fractures and for low-energy injuries, which were found to be predictive of union. A NURD score of 0 to 5 had a $2 \%$ chance of nonunion; 6 to $8,22 \%$; 9 to $11,42 \%$; and $>12,61 \%$.

Conclusions The proposed nonunion prediction model (NURDS) seems to have potential to allow clinicians to better determine which patients have a higher risk of nonunion. Future work should be directed at prospectively validating and enhancing this model.

Level of Evidence Level III, diagnostic study. 


\section{Introduction}

Tibial shaft fractures are the most common long bone fractures with incidences ranging from two per 1000 people to two per 10,000 people a year in the United States [3, 14]. The rate of tibial nonunions ranges between $5 \%$ and $15 \%$ [2, 22]. Hak et al. [23] estimate direct medical costs of USD 11,000 for a long bone nonunion, and Antonova et al. [1] estimate that a tibial shaft nonunion costs USD 14,000 more than a tibial shaft fracture that heals.

A clinical tool enabling surgeons to predict the likelihood of nonunion at the time of intramedullary (IM) nail fixation of tibial shaft fractures could change the management of patients at high risk of nonunion by allowing earlier intervention of the nonunion or other targeted interventions. Previous authors, including Audigé et al., Bhandari et al., and Fong et al. [2, 5, 19], have explored factors influencing nonunion in tibial shaft fractures at the time of definitive fixation. However, because these authors included many fractures with postoperative fracture gaps (known high nonunion risk), the authors were unable to elucidate other factors that may be associated with nonunion risk in fractures typically expected to achieve union without further intervention. It would be important to be able to identify early in the care of a patient whether a patient's fracture is likely to develop a nonunion or whether it is likely to heal uneventfully.

We therefore asked (1) whether data from medical records, fracture characteristics, and radiographs obtained at the time of fixation would identify features predictive of tibial fracture nonunion; and (2) whether this information could be used to create a model to assess the chance of nonunion at the time of IM nail fixation of the tibia.

\section{Patients and Methods}

This is a retrospective case-controlled study at a Level I trauma center in the United States. After receiving institutional review board approval, we (KO, MC, TC, TZ) reviewed the prospectively collected trauma database for tibial shaft fractures treated at our center from 2007 to 2014. These authors were not involved in the clinical care of the patients.

During the study period, 985 acute tibial shaft fractures were treated at our center (Fig. 1). Our standard is to treat the vast majority of tibial shaft fractures with reamed IM nail insertion. Exceptions are rare and typically include patients with large bone gaps or severe soft tissue injuries. All radiographs; clinic, operative, and discharge notes; and pertinent laboratory data were evaluated. We included patients aged 18 years and older (48 patients excluded). We

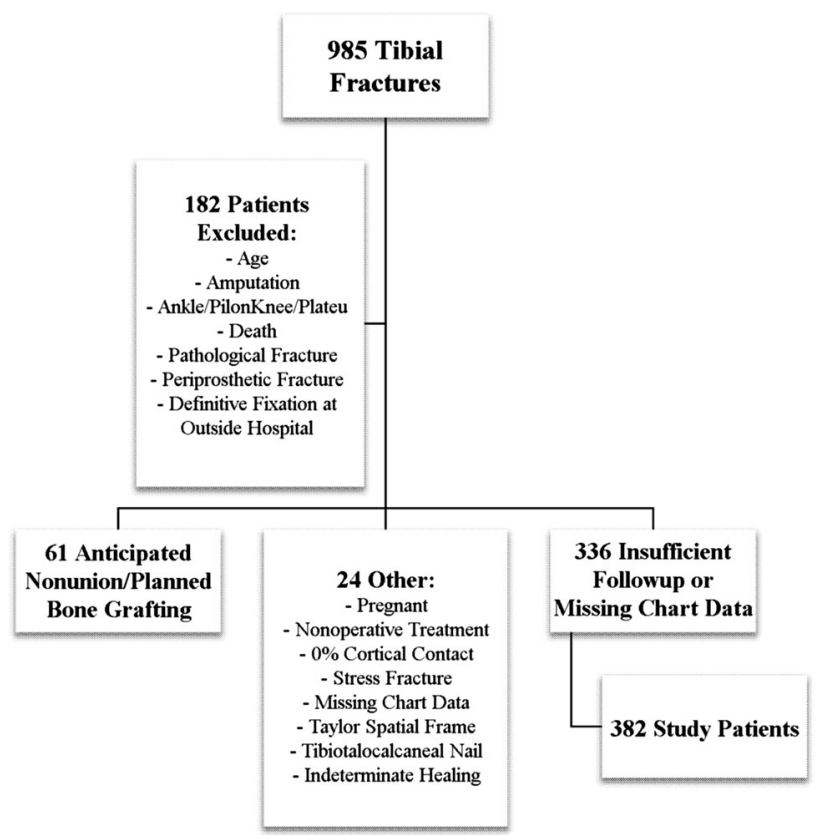

Fig. 1 A flowchart of study participation is shown. OSH = outside hospital.

followed patients until fracture healing or surgery for nonunion. Followup was a minimum of 9 months (336 patients excluded). We excluded patients with adequate followup but indeterminate healing status because their outcomes could not be determined (one patient). Patients were also excluded if they were treated with anything other than reamed IM nail fixation (one patient); had a tibiotalocalcaneal nail (14 patients); died before healing or nonunion (nine patients); had undergone early amputations (12 patients); had periprosthetic (three patients), stress (one patient), or pathologic fractures (three patients); had definitive fixation performed at a different hospital (four patients); or had fractures involving the tibial plafond (78 patients) or knee joints (25 patients) that required operative intervention separate from the IM nail. We excluded pregnant patients (two patients), those with insufficient cortical contact (one patient), those with missing chart data (three patients), and nonoperative patients (one patient). We also excluded patients with nonunion surgery planned before 3 months and those for whom the possibility of nonunion was noted before 3 months (61 patients). These patients were excluded because the attending surgeon was already anticipating nonunion, typically because of a fracture gap. Our final study cohort consisted of 382 adult patients treated with IM nails for tibial shaft fractures (nonunion $=56$; healed without further intervention $=326$ ) .

The goal of the study was to create a cohort of patients for whom union was expected without further intervention. To that end, no patients were included who had planned nonunion surgery, typically based on large fracture gap or 
bone defect. Large cortical defects are known to have high rates of nonunion [33].

Our primary outcome measure was unplanned surgery for nonunion. We defined nonunions as fractures that were expected to heal without further intervention that eventually, in the surgeon's judgment, required additional operative intervention beyond definitive fixation to establish bony union. Nonunion definition is an issue that pertains to all nonunion studies. No agreed-on and validated radiographic or clinical definition of nonunion has been reached to date. To address this issue, in contrast to previous authors, we excluded bone defects from the sample $[2,5,19]$. The bone defects can create statistical confusion because some of these cases are "critical" defects that have no chance of healing (eg, an 8-cm gap in a tibia). Even if "nonunion" surgery is performed at 6 months, one could argue that this is not a nonunion but rather a delay of prophylactic bone grafting that should have been done much earlier. Therefore, our definition is modeled after the nonunion definition presented by Mark Brinker: "A fracture that in the opinion of the treating physician has no possibility of healing without further intervention" [8]. This determination was made by the 13 surgeons included in this study. We did not perform any inter- or intraobserver testing of the surgeons' determinations. Based on the notes, the criteria used to determine union versus nonunion centered on pain at the fracture site, pain with weightbearing, callus, bridging callus, and presence of original fracture lines. Fracture nonunions radiographically typically showed bone resorption, lack of callus, lack of bridging callus, and persistence of fracture lines. By including a larger sample size than other studies and excluding patients with $0 \%$ cortical contact and all patients who had planned nonunion surgical interventions discussed within the first 3 months (bone grafting, dynamization, or nail exchange), we were able to isolate seven variables that promoted nonunion in our study patients. This revealed that although percent cortical contact does affect nonunion, other variables such as chronic disease, need for soft tissue coverage, and compartment syndrome also play a role.

If the surgeon declared the fracture healed, the patient was included in the study. Occasionally, a patient continued to be followed, but the surgeon did not declare the patient formally healed. In those cases, an already established radiographic measure of healing - the Radiographic Union Score for Tibial fractures (RUST) — was used by the first author (KO) $[9,28]$. If the fracture had a RUST $>10$, it was considered healed. Radiographs were reviewed using IMPAX 6.5 Client software (Agfa-Gevaert NV, Mortsel, Belgium). RUST were determined as described by Whelan et al. [41].

A chart review extracted data on the 35 variables theorized to contribute to delayed bone healing based on a review of the literature (Table 1). Certain variables thought to potentially contribute to nonunion were included despite lack of support in the literature. These variables were race,
Table 1. Variables and sources

\begin{tabular}{|c|c|}
\hline Variables & Literature sources* \\
\hline Age & Pro [2] \\
\hline Sex & Con $[26]$ \\
\hline Race & None \\
\hline Mechanism of injury & Pro $[2,26,27,35]$ \\
\hline $\begin{array}{l}\text { Percent cortical contact on } \\
\text { first postoperative films }\end{array}$ & Pro $[2,5,19,35]$ \\
\hline GSW & None \\
\hline Segmental & Pro $[34,35]$ \\
\hline Distal one-third or distal one-fourth & Pro $[2,26]$ \\
\hline Proximal one-third & Pro [40] \\
\hline Transverse & Pro [5] \\
\hline Spiral & Pro [34] \\
\hline Comminuted & $\begin{array}{l}\text { Pro }[26,34,40] \\
\text { Con }[35]\end{array}$ \\
\hline Oblique & None \\
\hline Bilateral tibial fractures & None \\
\hline Flap (IIIB) & Pro [11] \\
\hline Vascular injury & Pro [7] \\
\hline Open injury & Pro $[2,5]$ \\
\hline Weightbearing status postoperatively & $\begin{array}{l}\text { Pro }[15,26] \\
\text { Con }[35]\end{array}$ \\
\hline Fibular fracture fixation & $\begin{array}{l}\text { Pro }[15,38] \\
\text { Con }[39,42]\end{array}$ \\
\hline Compartment syndrome & Pro [32] \\
\hline NSAID use at admission & $\begin{array}{l}\text { Pro }[13,27] \\
\text { Con }[17,35]\end{array}$ \\
\hline NSAID use at discharge & $\begin{array}{l}\text { Pro }[13,27] \\
\text { Con }[17,35]\end{array}$ \\
\hline Opioid use at admission & Pro [12] \\
\hline Opioid use at discharge & Pro [12] \\
\hline Human immunodeficiency virus & $\begin{array}{l}\text { Pro [24] } \\
\text { Con [20] }\end{array}$ \\
\hline Hepatitis C & None \\
\hline Diabetes & Pro $[13,21,27]$ \\
\hline ASA score & Pro [16] \\
\hline Smoking status & $\begin{array}{l}\text { Pro }[13,21,31,36] \\
\text { Con }[29,35]\end{array}$ \\
\hline Alcohol use & Pro $[10,13,21]$ \\
\hline AO classification & $\begin{array}{l}\text { Pro }[30] \\
\text { Con }[2,22]\end{array}$ \\
\hline ISS score & Pro [30] \\
\hline TRISS score & Pro [30] \\
\hline ICU days & None \\
\hline
\end{tabular}

* Pro articles support a correlation between nonunion and the variable; Con articles show that the variable has no correlation with nonunion; GSW = gunshot wound; NSAID = nonsteroidal anti-inflammatory drug; ASA = American Society of Anesthesiologists; AO = Arbeitsgemeinschaft für Osteosynthesefragen; ISS = Injury Severity Score; TRISS = Trauma and Injury Severity Score; ICU = intensive care unit. 
gunshot wounds, oblique fractures, bilateral fractures, hepatitis $\mathrm{C}$, and number of days spent in the intensive care unit. Despite the morbidity caused by nonunions, the literature on the subject of contributing factors is sparse. Our review did not reveal any articles on the six variables noted. Nonetheless, these variables were easily collected on our patients and considering that there is no clear literature eliminating the association of these variables with nonunion, we elected to include them in our analysis.

Among the variables was postoperative cortical contact. Cortical contact was graded by the first author (KO) using the immediate postoperative AP and lateral view radiographs and counting anterior and posterior and medial and lateral cortices as $25 \%$ contact each. If the fracture gap was $3 \mathrm{~mm}$ or more, that particular cortex was assigned a $0 \%$ rating. Fractures were graded as $0 \%, 25 \%, 50 \%$, or $100 \%$ cortical contact. Any disagreements were resolved by one of the senior authors (RVO, JWN).

\section{Statistical Analysis}

Bivariate and multiple variable regression techniques and stepwise modeling approaches were used to examine the relationships between variables available during the index hospitalization and subsequent nonunion. The goal was to assess whether a predictive model for nonunion could be developed using the available covariate data gathered in the study. Bivariate and multiple logistic regression analyses of the database were conducted to identify baseline (ie, during the index hospitalization) factors that predict later nonunion. Bivariate analyses were used to explore the data and identify possible interaction and confounding effects.

Student's t-tests, chi-square tests, and bivariate logistic regression analyses were initially conducted to determine associations between the patient and injury characteristics and nonunion. Multiple logistic regression analyses were then used to further identify important predictors and possible interactions. First, a maximum model including all covariates as main effects was reduced by eliminating all predictors not statistically significant at the $\mathrm{p}<0.1$ level or with an odds ratio $>2$. Interaction effects were then examined, and model reduction was performed using $\mathrm{p}<0.05$ criteria. Variables with high bivariate relationships or strong previous clinical evidence of a causal relationship with nonunion were assessed with two widely used model fit statistics: the Akaike and Bayesian Information Criteria. Both the Akaike and Bayesian Information Criteria reward models that fit the data well and penalize models have more predictors than absolutely necessary. Thus, the Akaike and Bayesian Information Criteria take a U-shaped distribution of values as predictors are added with the optimum number of predictors occurring at the lowest point in the curve. The maximum model identified 12 factors with an association with nonunion. A multiple variable logistic regression model was used to examine the independent relationships between the 12 factors and nonunion. Factors predictive at $p<0.05$ were kept in Model 1 (Table 2). The six factors included in this model were percent cortical contact, open fractures, presence of compartment syndrome, need for a flap, chronic systemic conditions, and gender. Three additional factorsAmerican Society of Anesthesiologists (ASA) Physical Status score, current smoker status, and fibular fracture-were reexamined because of the combination of previous literature and strength of the bivariate relationships. Using the Akaike and Bayesian Information Criteria scores, we examined the effect of adding each of these factors back into the model. Akaike and Bayesian Information Criteria scores for the preliminary model were 272 and 300, respectively. Akaike and Bayesian Information Criteria scores rose consistently with the addition of the smoking and fibula variables. However, results were inconsistent for the addition of the ASA Physical Status score variable, which resulted in Akaike and Bayesian Information Criteria scores of 272 and 304, respectively. Based on these results, the ASA classification was retained in the final model (Table 3). Two factors-lowenergy injuries and spiral pattern fractures-were found to be perfectly predictive of union (see Tables 4 and 5 for bivariate analyses). These variables were included in the final clinical prediction tool but were not tested further as part of a multiple variable model because it is not possible to estimate a logistic model in which the predictors achieve complete separation of successes and failures in the outcome variable. A number of approaches can be used to address this issue; we chose to simply exclude the variable from the model considering that the goal of this analysis was to obtain a clinically meaningful predictive model rather than to obtain precise estimates of the effect of each variable on nonunion [25]. Statistical analyses were conducted using STATA 13 software (StataCorp LP, College Station, TX, USA).

The patient cohort of 382 participants ranged in age from 18 to 85 years (average age, 39 years). The patients were $75 \%$ male, $60 \%$ white, and $32 \%$ black. Ninety percent of the fractures were high-energy injuries. The average Injury Severity Score was 16.5.

For the study, 985 patients were potentially eligible. We excluded 48 patients who were younger than 18 years, 12 who had undergone early amputations, 103 who had fractures of the tibiotalar or knee joints requiring fixation apart from the nail, nine who died before completing followup, four who had undergone definitive fixation at a different hospital, three who had missing chart data, one who was treated nonoperatively, three who had pathologic fractures, three who had periprosthetic fractures, 61 who had anticipated nonunion, two who were pregnant and had limited radiographic followup, one who had a stress fracture, one 
Table 2. Preliminary multiple variable logistic regression model for nonunion

\begin{tabular}{|c|c|c|c|c|c|}
\hline Nonunion factors & Odds ratio & Standard error & $\mathrm{Z}$ value & $\mathrm{p}$ value & $95 \% \mathrm{CI}$ \\
\hline Percent cortical contact & 0.984 & 0.00691 & -2.64 & 0.008 & $0.968-0.995$ \\
\hline Open & 2.43 & 0.899 & 2.41 & 0.016 & $1.18-5.02$ \\
\hline Compartment syndrome & 4.21 & 2.93 & 2.06 & 0.039 & $1.07-16.49$ \\
\hline IIIB fracture & 5.54 & 2.55 & 3.72 & 0.000 & $2.25-13.65$ \\
\hline Chronic disease (Hep/HIV/D) & 3.96 & 1.82 & 3.01 & 0.003 & $1.61-9.73$ \\
\hline Female sex & 0.420 & 0.189 & -1.92 & 0.054 & $0.174-1.02$ \\
\hline
\end{tabular}

$\mathrm{CI}=$ confidence interval; Hep $=$ hepatitis $\mathrm{C} ; \mathrm{D}=$ diabetes.

Table 3. Final multiple variable logistic regression model for nonunion

\begin{tabular}{lllc}
\hline Nonunion factors & Odds ratio & p value & 95\% CI \\
\hline Percent cortical contact & 0.982 & 0.01 & $0.969-0.996$ \\
Open & 2.48 & 0.01 & $1.20-5.14$ \\
Compartment syndrome & 4.13 & 0.05 & $1.03-6.59$ \\
IIIB fracture & 5.17 & 0.00 & $2.07-12.89$ \\
Chronic disease (Hep/HIV/D) & 3.12 & 0.00 & $1.22-8.01$ \\
Female sex & 0.416 & 0.05 & $0.17-1.00$ \\
ASA score & 1.49 & 0.13 & $0.886-2.51$
\end{tabular}

$\mathrm{CI}=$ confidence interval; Hep = hepatitis C; D = diabetes; ASA = American Society of Anesthesiologists.

treated with a Taylor spatial frame, 14 with tibiotalocalcaneal nails, one with insufficient cortical contact, one with indeterminate fracture healing, and 336 with insufficient followup. Three hundred eighty-two patients remained for inclusion in the study (Table 6).

\section{Results}

Of the 35 variables, 14 were identified as being predictive of nonunion according to our prespecified definitions; these were: percent cortical contact, open fractures, ASA Physical Status score, compartment syndrome, flap, comminuted fractures, AO Type B or C, fibular fracture, Abbreviated Injury Scale spine severity score $\geq 3$, current smoker status, HIV-positive status, hepatitis C-positive status, history of diabetes, and male gender. However, because of small sample sizes, three variables (HIV-positive status, hepatitis C-positive status, and history of diabetes) were combined into a single chronic systemic disease variable, leaving a total of 12 variables. The 12 variables were reduced to six variables by using a multiple variable logistic regression model. The factors included are percent cortical contact, open fractures, presence of a compartment syndrome, need for a flap, chronic systemic conditions, and gender. Additionally, ASA Physical Status score was included as a variable based on statistical criteria discussed in the Patients and Methods section. Two factors-low-energy injuries and spiral pattern fractures-were found to be perfectly predictive of union and were also included in the final model (Table 7). Smoking was exhaustively statistically analyzed in this data set and found to have no significance at the $\mathrm{p}<0.05$ level.

A clinical nonunion prediction score was created based on the odds ratios in the final multiple variable model: the Nonunion Risk Determination (NURD) score (Fig. 2). The NURD score assigns 5 points for flaps, 4 points for compartment syndrome, 3 points for chronic condition(s), 2 points for open fractures, 1 point for male gender, 1 point per ASA Physical Status score, and 1 point per percent of cortical contact. One point each was subtracted from the score for spiral fractures and low-energy injuries, which were found to be predictive of union. Patients with a NURD score of 0 to 5 (four of 232 patients) had a $2 \%$ chance of nonunion (95\% confidence interval [CI], 0.053.39). Patients with a score of 6 to 8 (22 of 101 patients) had a $22 \%$ chance of nonunion (95\% CI, 13.92-30.08). Patients with a score of 9 to 11 (13 of 31 patients) had a $42 \%$ chance of nonunion (95\% CI, 24.63-59.37). Patients with a score $>12$ (11 of 18 patients) had a $61 \%$ chance of nonunion (95\% CI, 38.47-83.53).

\section{Discussion}

Being able to predict tibial shaft fracture nonunions at the time of definitive fixation would be useful for clinicians 
Table 4. Bivariate relationships between clinical and patient characteristics and nonunion: categorical variables

\begin{tabular}{|c|c|c|c|c|c|c|c|}
\hline Characteristic & Yes/no & Number & Union & Nonunion & Odds ratio & $\begin{array}{l}\text { Confidence } \\
\text { interval }\end{array}$ & $\begin{array}{l}\text { Chi square } \\
\text { p value }\end{array}$ \\
\hline \multirow[t]{2}{*}{ AO classification } & A & $148 / 382(39 \%)$ & $132 / 326(40 \%)$ & $16 / 56(29 \%)$ & B: 1.86 & $0.94-3.7$ & 0.09 \\
\hline & $\mathrm{B}$ or $\mathrm{C}$ & $234 / 382(61 \%)$ & $194 / 326(60 \%)$ & $40 / 56(71 \%)$ & C: 1.5 & $0.71-3.16$ & \\
\hline \multirow[t]{2}{*}{ GSW } & No & $374 / 382(98 \%)$ & $320 / 326(98 \%)$ & $54 / 56(96 \%)$ & 1.98 & $0.39-10.0$ & 0.4 \\
\hline & Yes & $8 / 382(2 \%)$ & $6 / 326(2 \%)$ & $2 / 56(4 \%)$ & & & \\
\hline \multirow[t]{2}{*}{ Segmental } & No & $330 / 382(86 \%)$ & $282 / 326(87 \%)$ & $48 / 56(86 \%)$ & 1.07 & $0.47-2.41$ & 0.87 \\
\hline & Yes & $52 / 382(14 \%)$ & $44 / 326(13 \%)$ & $8 / 56(14 \%)$ & & & \\
\hline \multirow[t]{2}{*}{ Distal one-third } & No & $216 / 382(57 \%)$ & $182 / 326(56 \%)$ & $34 / 56(61 \%)$ & 0.82 & $0.46-1.46$ & 0.5 \\
\hline & Yes & $166 / 382(43 \%)$ & $144 / 326(44 \%)$ & $22 / 56(39 \%)$ & & & \\
\hline \multirow[t]{2}{*}{ Distal one-fourth } & No & $262 / 382(69 \%)$ & $223 / 326(68 \%)$ & $39 / 56(70 \%)$ & 0.95 & $0.51-1.76$ & 0.89 \\
\hline & Yes & $119 / 382(31 \%)$ & $102 / 326(32 \%)$ & $17 / 56(30 \%)$ & & & \\
\hline \multirow[t]{2}{*}{ Proximal one-third } & No & $356 / 382(93 \%)$ & $302 / 326(93 \%)$ & $54 / 56(96 \%)$ & 0.49 & $0.11-2.13$ & 0.34 \\
\hline & Yes & $25 / 382(7 \%)$ & $23 / 326(7 \%)$ & $2 / 56(4 \%)$ & & & \\
\hline \multirow[t]{2}{*}{ Transverse } & No & $261 / 382(68 \%)$ & $222 / 326(68 \%)$ & $39 / 56(70 \%)$ & 0.94 & $0.51-1.75$ & 0.9 \\
\hline & Yes & $120 / 382(31 \%)$ & $103 / 326(32 \%)$ & $17 / 56(30 \%)$ & & & \\
\hline \multirow[t]{2}{*}{ Spiral } & No & $337 / 382(88 \%)$ & $281 / 326(86 \%)$ & $56 / 56(100 \%)$ & & & 0.003 \\
\hline & Yes & $45 / 382(12 \%)$ & $45 / 326(14 \%)$ & $0 / 56(0 \%)$ & & & \\
\hline \multirow[t]{2}{*}{ Comminuted } & No & $159 / 382(42 \%)$ & $142 / 326(44 \%)$ & $17 / 56(30 \%)$ & 1.77 & $0.96-3.26$ & 0.07 \\
\hline & Yes & $223 / 382(58 \%)$ & $184 / 326(56 \%)$ & $39 / 56(70 \%)$ & & & \\
\hline \multirow[t]{2}{*}{ Oblique } & No & $298 / 382(78 \%)$ & $257 / 326(79 \%)$ & $41 / 56(73 \%)$ & 1.36 & $0.7-2.61$ & 0.35 \\
\hline & Yes & $84 / 382(22 \%)$ & $69 / 326(21 \%)$ & $15 / 56(27 \%)$ & & & \\
\hline \multirow[t]{2}{*}{ Fibular fracture fixation } & No & $369 / 382(97 \%)$ & $318 / 326(96 \%)$ & $51 / 56(91 \%)$ & 3.9 & $1.2-12.4$ & 0.02 \\
\hline & Yes & $13 / 382(3 \%)$ & $8 / 326(4 \%)$ & $5 / 56(9 \%)$ & & & \\
\hline \multirow{4}{*}{$\begin{array}{l}\text { Percent cortical contact on } \\
\text { first postoperative films }\end{array}$} & $25 \%$ & $17 / 382(5 \%)$ & $12 / 326(4 \%)$ & $5 / 56(9 \%)$ & 0.98 & $0.96-0.99$ & 0.001 \\
\hline & $50 \%$ & $78 / 382(20 \%)$ & $59 / 326(18 \%)$ & $19 / 56(34 \%)$ & & & \\
\hline & $75 \%$ & $124 / 382(32 \%)$ & $103 / 326(31 \%)$ & $21 / 56(37 \%)$ & & & \\
\hline & $100 \%$ & $163 / 382(43 \%)$ & $152 / 326(47 \%)$ & $11 / 56(20 \%)$ & & & \\
\hline \multirow[t]{2}{*}{ Open injury } & No & $189 / 382(49 \%)$ & $176 / 326(54 \%)$ & $13 / 56(23 \%)$ & 3.9 & $2.0-7.5$ & $<0.001$ \\
\hline & Yes & $193 / 382(51 \%)$ & $150 / 326(46 \%)$ & $43 / 56(77 \%)$ & & & \\
\hline \multirow[t]{3}{*}{ ASA score } & 1 & $61 / 382(16 \%)$ & $57 / 326(17 \%)$ & $4 / 56(7 \%)$ & 2.7 & $0.78-9.13$ & 0.02 \\
\hline & 2 & $206 / 382(54 \%)$ & $179 / 326(55 \%)$ & $27 / 56(48 \%)$ & & & \\
\hline & 3 & $115 / 382(30 \%)$ & $90 / 326(28 \%)$ & $25 / 56(45 \%)$ & & & \\
\hline \multirow[t]{2}{*}{ Smoker } & No & $229 / 382(60 \%)$ & $202 / 326(62 \%)$ & $27 / 56(48 \%)$ & 1.8 & $1.0-3.2$ & 0.05 \\
\hline & Yes & $153 / 382(40 \%)$ & $124 / 326(38 \%)$ & $29 / 56(52 \%)$ & & & \\
\hline \multirow[t]{2}{*}{ EtOH use } & None or social & $278 / 382(73 \%)$ & $242 / 326(74 \%)$ & $36 / 56(64 \%)$ & 1.6 & $0.88-2.92$ & 0.13 \\
\hline & Heavy & $104 / 382(27 \%)$ & $84 / 326(26 \%)$ & $20 / 56(36 \%)$ & & & \\
\hline \multirow[t]{2}{*}{ HIV } & No & $367 / 372(99 \%)$ & $314 / 317(99 \%)$ & $53 / 55(96 \%)$ & 4 & $0.64-24.2$ & 0.14 \\
\hline & Yes & $5 / 372(1 \%)$ & $3 / 317(1 \%)$ & $2 / 55(4 \%)$ & & & \\
\hline \multirow[t]{2}{*}{ Hepatitis C } & No & $364 / 373(96 \%)$ & $314 / 319(98 \%)$ & $50 / 54(93 \%)$ & 5 & $1.3-19$ & 0.02 \\
\hline & Yes & $9 / 373(4 \%)$ & $5 / 319(2 \%)$ & $4 / 54(7 \%)$ & & & \\
\hline \multirow[t]{2}{*}{ NSAID use at admission } & No & $341 / 364(94 \%)$ & 293/314 (93\%) & $48 / 50(96 \%)$ & 0.6 & $0.13-2.56$ & 0.47 \\
\hline & Yes & $23 / 364(6 \%)$ & $21 / 314(7 \%)$ & $2 / 50(4 \%)$ & & & \\
\hline \multirow[t]{2}{*}{ NSAID use at discharge } & No & $322 / 369(87 \%)$ & $278 / 316(88 \%)$ & $44 / 53(83 \%)$ & 1.5 & $0.7-3.3$ & 0.32 \\
\hline & Yes & $47 / 369(13 \%)$ & $38 / 316(12 \%)$ & $9 / 53(17 \%)$ & & & \\
\hline \multirow[t]{2}{*}{ Opioid use at admission } & No & $341 / 365(93 \%)$ & $294 / 315(93 \%)$ & $47 / 50(94 \%)$ & 0.9 & $0.26-3.1$ & 0.86 \\
\hline & Yes & $24 / 365(7 \%)$ & $21 / 315(7 \%)$ & $3 / 50(6 \%)$ & & & \\
\hline Opioid use at discharge & No & $11 / 375(3 \%)$ & $10 / 321(3 \%)$ & $1 / 54(2 \%)$ & 1.7 & $0.21-13.6$ & 0.62 \\
\hline & Yes & $364 / 375(97 \%)$ & $311 / 321(97 \%)$ & $53 / 54(98 \%)$ & & & \\
\hline
\end{tabular}


Table 4. continued

\begin{tabular}{|c|c|c|c|c|c|c|c|}
\hline Characteristic & Yes/no & Number & Union & Nonunion & Odds ratio & $\begin{array}{l}\text { Confidence } \\
\text { interval }\end{array}$ & $\begin{array}{l}\text { Chi square } \\
\mathrm{p} \text { value }\end{array}$ \\
\hline \multirow[t]{2}{*}{ Diabetes } & No & $355 / 378(94 \%)$ & $306 / 323(95 \%)$ & $49 / 55(89 \%)$ & 2.2 & $0.83-5.9$ & 0.11 \\
\hline & Yes & $23 / 378(6 \%)$ & $17 / 323(5 \%)$ & $6 / 55(11 \%)$ & & & \\
\hline \multirow[t]{2}{*}{ Compartment syndrome } & No & $369 / 382(97 \%)$ & $318 / 326(98 \%)$ & $51 / 56(91 \%)$ & 4 & $1.3-12.6$ & 0.01 \\
\hline & Yes & $13 / 382(3 \%)$ & $8 / 326(2 \%)$ & $5 / 56(9 \%)$ & & & \\
\hline \multirow[t]{2}{*}{ Weightbearing } & Non-WB & $232 / 382(61 \%)$ & $193 / 326(59 \%)$ & $39 / 56(70 \%)$ & 1.6 & $0.86-2.9$ & 0.14 \\
\hline & WBAT & $150 / 382(39 \%)$ & $133 / 326(41 \%)$ & $17 / 56(30 \%)$ & & & \\
\hline \multirow[t]{2}{*}{ Vascular injury } & No & $374 / 382(98 \%)$ & $320 / 326(98 \%)$ & $54 / 56(96 \%)$ & 2 & $0.39-10$ & 0.4 \\
\hline & Yes & $8 / 382(2 \%)$ & $6 / 326(2 \%)$ & $2 / 56(4 \%)$ & & & \\
\hline \multirow[t]{2}{*}{ Flap } & No & $355 / 382(93 \%)$ & $314 / 326(96 \%)$ & $41 / 56(73 \%)$ & 9.6 & $4.2-21.9$ & $<0.001$ \\
\hline & Yes & $27 / 382(7 \%)$ & $12 / 326(4 \%)$ & $15 / 56(27 \%)$ & & & \\
\hline \multirow[t]{2}{*}{ Male sex } & No & $289 / 382(76 \%)$ & $241 / 326(74 \%)$ & $48 / 56(86 \%)$ & 0.47 & $0.21-1$ & 0.06 \\
\hline & Yes & $93 / 382(24 \%)$ & $85 / 326(26 \%)$ & $8 / 56(14 \%)$ & & & \\
\hline \multirow[t]{2}{*}{ Race } & White & $232 / 382(61 \%)$ & $200 / 326(61 \%)$ & $32 / 56(57 \%)$ & 1.2 & $0.7-2.1$ & 0.55 \\
\hline & Nonwhite & $150 / 382(39 \%)$ & $126 / 326(39 \%)$ & $24 / 56(43 \%)$ & & & \\
\hline \multirow[t]{2}{*}{ Bilateral tibial fractures } & No & $344 / 382(90 \%)$ & $296 / 326(91 \%)$ & $48 / 56(86 \%)$ & 1.64 & $0.71-3.8$ & 0.24 \\
\hline & Yes & $38 / 382(10 \%)$ & $30 / 326(9 \%)$ & $8 / 56(14 \%)$ & & & \\
\hline \multirow[t]{2}{*}{ Mechanism of injury } & Low-energy & $39 / 382(10 \%)$ & $39 / 326(12 \%)$ & $0 / 56(0 \%)$ & & & 0.006 \\
\hline & High-energy & $343 / 382(90 \%)$ & $287 / 326(88 \%)$ & $56 / 56(100 \%)$ & & & \\
\hline
\end{tabular}

$\mathrm{AO}=$ Arbeitsgemeinschaft für Osteosynthesefragen; GSW = gunshot wound; ASA = American Society of Anesthesiologists; EtOH = ethyl alcohol; $\mathrm{WB}=$ weightbearing; $\mathrm{WBAT}=$ weightbearing as tolerated.

Table 5. Bivariate relationships between clinical and patient characteristics and nonunion: continuous variables

\begin{tabular}{|c|c|c|c|c|c|}
\hline Characteristic & Number & Mean & Odds ratio & $95 \% \mathrm{CI}$ & t-test $p$ value \\
\hline ISS & & & & & $\operatorname{Pr}(|\mathrm{T}|>|\mathrm{t}|)=0.18$ \\
\hline Union & $326 / 382(85 \%)$ & 16.18 & 1.02 & $15.07-17.29$ & \\
\hline Nonunion & $56 / 382(15 \%)$ & 18.2 & & $15.11-21.28$ & \\
\hline Age (years) & & & & & $\operatorname{Pr}(|\mathrm{T}|>|\mathrm{t}|)=0.38$ \\
\hline Union & $326 / 382(85 \%)$ & 38.93 & 1.01 & $37.21-40.65$ & \\
\hline Nonunion & $56 / 382(15 \%)$ & 40.89 & & $37.59-44.19$ & \\
\hline TRISS & & & & & $\operatorname{Pr}(|\mathrm{T}|>|\mathrm{t}|)=0.09$ \\
\hline Union & $311 / 365(85 \%)$ & 0.954 & 0.19 & $0.942-0.966$ & \\
\hline Nonunion & $54 / 365(15 \%)$ & 0.922 & & $0.873-0.971$ & \\
\hline ICU days & & & & & $\operatorname{Pr}(|\mathrm{T}|>|\mathrm{t}|)=0.39$ \\
\hline Union & $311 / 365(85 \%)$ & 2.99 & 1.01 & $2.14-3.84$ & \\
\hline Nonunion & $54 / 365(15 \%)$ & 4 & & $1.49-6.50$ & \\
\hline
\end{tabular}

CI = confidence interval; ISS = Injury Severity Score; TRISS = Trauma and Injury Severity Score; ICU = intensive care unit.

and patients. Early interventions may abbreviate the time of disability in high-risk patients and the prediction can be reassuring to those at low risk of nonunion. Although attempts have been made to create an early tibial shaft nonunion prediction model, the models included large postoperative fracture gaps, were clinically cumbersome, or both $[2,5,19]$. The inclusion of fractures with $0 \%$ cortical continuity (a fracture group known to have high nonunion rates) tends to lead to statistically overemphasizing the role of fracture gap in nonunions and underrepresenting other factors that may play a role. Considering that the exact size of a "critical gap" that requires treatment is unknown and considering that clinicians are already well aware that large fracture gaps in open fractures are less likely to heal, we did not include patients with any gaps in our study. We understand that postoperative fracture gap does play an important role in nonunion, and we think that most clinicians do not require 
assistance in predicting nonunions among fractures that have sizeable gaps postoperatively [18]. The treatment dilemma that currently exists concerns the fracture with at least some cortical contact postoperatively [19, 33]. We were successful at developing a time zero model that allowed us to predict, based on nine common variables, which fractures were most and least likely to go on to nonunion among a cohort of fractures that were initially expected to heal uneventfully. The NURD score allows clinicians to quickly put patients into one of four categories of nonunion risk and to then communicate the information to patients.

Our study has inherent weaknesses typical of retrospective study designs. We had a number of ineligible patients, including 331 patients who failed to followup to healing or to an intervention for nonunion. It is possible that many of those patients who did not followup had complications and sought care elsewhere, and our model might have shifted if we had outcome data on all of them. The exclusion of so many patients may be seen as a limitation but was done to ensure that we included only patients known to have healed

Table 6. Excluded compared with included patients

\begin{tabular}{lll}
\hline Variable & $\begin{array}{l}\text { Excluded because } \\
\text { of insufficient } \\
\text { followup }(\mathrm{n}=336)\end{array}$ & $\begin{array}{l}\text { Included and followed } \\
\text { until healing or } \\
\text { nonunion }(\mathrm{n}=382)\end{array}$ \\
\hline $\begin{array}{l}\text { Average age (years) } \\
\text { Sex }\end{array}$ & 38.6 & 39.3 \\
Male & 259 & 289 \\
Female & 77 & 93 \\
AO classification & & $148(39 \%)$ \\
A & $160(48 \%)$ & $130(34 \%)$ \\
B & $121(36 \%)$ & $104(27 \%)$ \\
C & $55(16 \%)$ &
\end{tabular}

$\mathrm{AO}=$ Arbeitsgemeinschaft für Osteosynthesefragen. or gone on to nonunion, and these were all patients who were expected to go on to an uneventful union at the time of fixation. This approach allowed us to address the cases of unexpected nonunion that are not easily predictable and are vexing to patients and clinicians. The study used data from one trauma center, perhaps limiting the generalizability of the findings. The population was young (average age, 39 years) and predominantly a high-energy cohort, so the results may not apply as well to an elderly, lower energy population. The intervention was limited to reamed IM nails and cannot predict nonunions in fractures treated with other interventions. During the course of this study, the standard of care for open and closed tibial shaft fractures was reamed IM nail fixation. The vast majority of our patients underwent IM nail insertion. Of 985 patients with tibial shaft fractures assessed, only two were excluded for fixation other than reamed IM nail fixation (one Taylor spatial frame fixation and one nonoperative treatment). The results are limited to the variables that we assessed in this study. The question of nonunion definition pertains to all nonunion studies because no validated and agreed-on clinical or radiographic

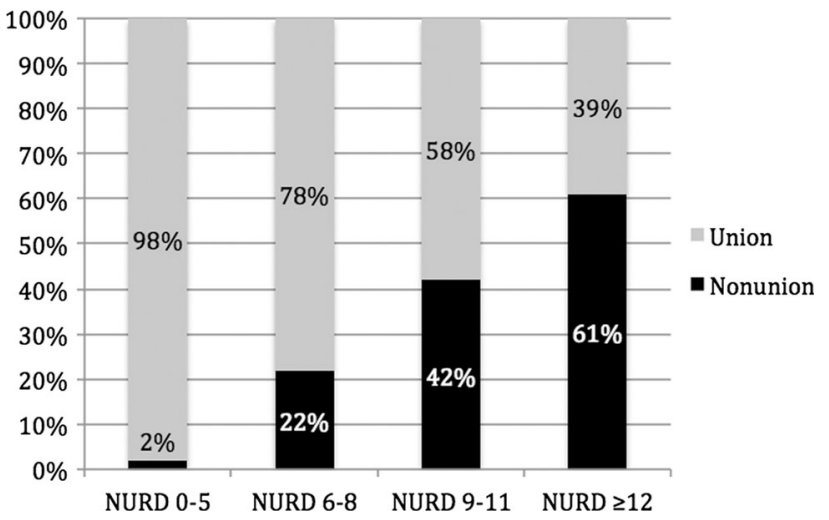

Fig. 2 The graph depicts NURD scoring.

Table 7. Nonunion risk determination scoring matrix

\begin{tabular}{|c|c|c|c|c|c|c|}
\hline-1 Point & 0 Points & 1 Point & 2 Points & 3 Points & 4 Points & 5 Points \\
\hline $\begin{array}{l}\text { Low-energy } \\
\text { fractures }\end{array}$ & $\begin{array}{l}100 \% \text { Cortical } \\
\text { contact }\end{array}$ & $\begin{array}{l}75 \% \text { Cortical } \\
\text { contact }\end{array}$ & $\begin{array}{l}50 \% \text { Cortical } \\
\text { contact }\end{array}$ & $25 \%$ Cortical contact & & \\
\hline \multirow{6}{*}{$\begin{array}{l}\text { Spiral pattern } \\
\text { fractures }\end{array}$} & & ASA 1 & ASA 2 & ASA 3-4 & & \\
\hline & Female & Male & & & & \\
\hline & Closed fractures & & Open fractures & & & \\
\hline & & & & $\begin{array}{l}\text { Chronic disease (HepC/ } \\
\text { HIV/DM) }\end{array}$ & & \\
\hline & & & & & $\begin{array}{l}\text { Compartment } \\
\text { syndrome }\end{array}$ & \\
\hline & & & & & & $\begin{array}{l}\text { Flap coverage } \\
\text { required }\end{array}$ \\
\hline
\end{tabular}

$\mathrm{ASA}=$ American Society of Anesthesiologists; HepC $=$ hepatitis $\mathrm{C} ; \mathrm{DM}=$ diabetes mellitus. 
definition of nonunion is available. We defined nonunion as fractures requiring additional surgical intervention beyond definitive fixation. This definition has precedents in the work of others [1, 4-6, 8]. It was promulgated by Mark Brinker MD [8], but has the disadvantage of relying on the treating physician to declare a nonunion. No interobserver verification of the nonunion was obtained from a disinterested party. Although this is a serious limitation to our study, it is the same limitation that plagues every study on this topic because no currently agreed-on and validated definition of nonunion is available and having multiple surgeons agree on or disagree on a potentially flawed and certainly not validated definition of nonunion may not advance the argument.

Researchers have attempted, with some success, to determine variables associated with tibial nonunions early in the course of treatment. Bhandari et al. [5] retrospectively studied 192 patients and devised a model with which $<50 \%$ cortical contact, open fractures, and transverse fractures predicted nonunion. Although the model presented by Bhandari et al. is simple and user-friendly, it has weaknesses such as the inclusion of 51 (27\%) of 192 fractures with $0 \%$ cortical contact postoperatively (fracture gaps) that may result in too much statistical weight being given to percent cortical contact. Furthermore, the group had heterogenous treatments with plating, external fixation, and reamed and unreamed IM nail fixation. Fong et al. [19] retrospectively studied 200 patients treated with IM nails or plating and found that $<25 \%$ cortical contact was the only factor predictive of nonunion in their series. Percent cortical contact was strongly associated with reoperation and nonunion, and all 27 patients who underwent reoperation for nonunion had $<25 \%$ cortical contact. Audigé et al. [2] prospectively followed 416 tibial shaft fractures and developed a path diagram to model nonunion risk. The variables they identified were open injuries, distal third of the shaft fractures, and visible fracture diastasis after fixation. The study included various treatment options, including external fixation, reamed and unreamed IM nail fixation, and plating. Parsing out reamed IM nails, their study was limited to 106 fractures with four nonunions and six delayed unions. The majority of the nonunions among the 416 fractures were noted in patients treated with external fixation and unreamed tibial nail fixation, neither of which was included in our study. The study by Audigé et al. found that open fracture, distal shaft fractures, and fracture gap helped predict nonunion. However, similar to the studies by Bhandari et al. and Fong et al., the study by Audigé et al. included 101 (24\%) fractures with a "visible fracture gap" after definitive fixation. Although the path diagram created is comprehensive, it is cumbersome to the clinician at the point of care, and the inclusion of additional treatments hampers the ability of the study to address nonunions with reamed IM nail fixation.
Lack et al. [29] established a 4-month postoperative nonunion prediction model based on cortical bridging of one cortex. Although innovative, this model is not useful at time zero. Using a more homogeneous set of treatments and injuries than previous investigators used, we elucidated more subtle variables that allowed us to create a time zero tibial shaft fracture nonunion prediction model. This model, although not perfectly predictive of nonunion, provides clinicians with an easy-to-understand scoring system that stratifies the risk of nonunion at time zero and at early clinic visits. This model has already been developed into a webbased application (available at www.shocknurd.org) and is in the process of becoming a smartphone application. This model allows clinicians and patients to implement interventions aimed at reducing the nonunion risk or opt to surgically intervene earlier to promote union when appropriate.

Two particular variables that are widely thought to contribute to nonunion were not identified statistically in our study: smoking and Gustilo and Anderson Type IIIC open tibial fractures. Despite evidence that cigarette smoking plays a role in nonunion and delayed union [13, 21, 31, 36], precedents for smoking not being associated with nonunion are also reported [5, 19]. Some evidence supports IIIC fractures being correlated with nonunions [37]. Despite a $25 \%$ nonunion frequency among these fractures in our study, IIIC injuries were not statistically correlated with increased nonunion risk, possibly because of the small number of IIIC injuries (eight fractures) in our sample.

In summary, we determined that a number of factors predict nonunions and can be formed into a nonunion prediction model that will allow clinicians to better predict the likelihood of nonunion among fractures that are clinically expected to heal. The ability to predict nonunion early in the patient's course may help guide patients and clinicians regarding when patience is the best approach because union is likely and when interventions aimed at enhancing healing of the fracture through earlier surgical interventions may be reasonable. The proposed nonunion prediction model (NURDS) seems to have potential to allow clinicians to better determine which patients have a higher risk of nonunion. Future work should be directed at prospectively validating and enhancing this model.

Acknowledgments We thank Dori Kelly MA, Senior Editor, for proofreading and organizing the paper and Andrew Burton of Enki Solutions, Chicago, Illinois, for web and smartphone app design.

\section{References}

1. Antonova E, Le TK, Burge R, Mershon J. Tibia shaft fractures: costly burden of nonunions. BMC Musculoskelet Disord. 2013;14:42. 
2. Audigé L, Griffin D, Bhandan M, Kellam J, Rüedi TP. Path analysis of factors for delayed healing and nonunion in 416 operatively treated tibial shaft fractures. Clin Orthop Relat Res. 2005;438:221-232.

3. Bengnér $\mathrm{U}$, Ekbom $\mathrm{T}$, Johnell $\mathrm{O}$, Nilsson BE. Incidence of femoral and tibial shaft fractures: epidemiology 1950-1983 in Malmö, Sweden. Acta Orthop Scand. 1990;61:251-254.

4. Bhandari M, Guyatt GH, Swiontkowski MF, Tornetta P III, Sprague S, Schemitsch EH. A lack of consensus in the assessment of fracture healing among orthopaedic surgeons. J Orthop Trauma. 2002;16:562-566.

5. Bhandari M, Tornetta P III, Sprague S, Najibi S, Petrisor B, Griffith L, Guyatt GH. Predictors of reoperation following operative management of fractures of the tibial shaft. J Orthop Trauma. 2003;17:353-361.

6. Bishop JA, Palanca AA, Bellino MJ, Lowenberg DW. Assessment of compromised fracture healing. J Am Acad Orthop Surg. 2012;20:273-282.

7. Brinker MR, Bailey DE Jr. Fracture healing in tibia fractures with an associated vascular injury. J Trauma. 1997;42:11-19.

8. Brinker MR, O'Connor DP. Nonunions: evaluation and treatment. In: Browner BD, Jupiter JB, Levine AM, Trafton PG, Krettek C, eds. Skeletal Trauma: Basic Science, Management, and Reconstruction. 4th ed. Philadelphia, PA, USA: WB Saunders; 2009:637-718.

9. Cekic E, Alici E, Yesil M. Reliability of the radiographic union score for tibial fractures. Acta Orthop Traumatol Turc. 2014;48: 533-540.

10. Chakkalakal DA, Novak JR, Fritz ED, Moliner TJ, McVicker DL, Garvin KL, McGuire MH, Donohue TM. Inhibition of bone repair in a rat model for chronic and excessive alcohol consumption. Alcohol. 2005;36:201-214.

11. Choudry U, Moran S, Karacor Z. Soft-tissue coverage and outcome of Gustilo grade IIIB midshaft tibia fractures: a 15-year experience. Plast Reconstr Surg. 2008;122:479-485.

12. Chrastil J, Sampson C, Jones KB, Higgins TF. Postoperative opioid administration inhibits bone healing in an animal model. Clin Orthop Relat Res. 2013;471:4076-4081.

13. Copuroglu C, Calori GM, Giannoudis PV. Fracture non-union: who is at risk? Injury. 2013;44:1379-1382.

14. Court-Brown CM, McBirnie J. The epidemiology of tibial fractures. J Bone Joint Surg Br. 1995;77:417-421.

15. DeLee JC, Heckman JD, Lewis AG. Partial fibulectomy for ununited fractures of the tibia. J Bone Joint Surg Am. 1981;63: 1390-1395.

16. Ding L, He Z, Xiao H, Chai L, Xue F. Factors affecting the incidence of aseptic nonunion after surgical fixation of humeral diaphyseal fracture. J Orthop Sci. 2014;19:973-977

17. Dodwell ER, Latorre JG, Parisini E, Zwetter E, Chandra D, Mulpuri K, Snyder B. NSAID exposure and risk of nonunion: a meta-analysis of case-control and cohort studies. Calcif Tissue Int. 2010;87:193-202.

18. Drosos GI, Bishay M, Karnezis IA, Alegakis AK. Factors affecting fracture healing after intramedullary nailing of the tibial diaphysis for closed and grade I open fractures. J Bone Joint Surg Br. 2006;88:227-231.

19. Fong K, Truong V, Foote CJ, Petrisor B, Williams D, Ristevski B, Sprague S, Bhandari M. Predictors of nonunion and reoperation in patients with fractures of the tibia: an observational study. BMC Musculoskelet Disord. 2013;14:103.

20. Gardner RO, Bates JH, Ng'oma E, Harrison WJ. Fracture union following internal fixation in the HIV population. Injury. 2013; 44:830-833.

21. Gaston MS, Simpson AH. Inhibition of fracture healing. $J$ Bone Joint Surg Br. 2007;89:1553-1560
22. Gaston P, Will E, Elton RA, McQueen MM, Court-Brown CM. Fractures of the tibia: can their outcome be predicted. $J$ Bone Joint Surg Br. 1999;81:71-76.

23. Hak DJ, Fitzpatrick D, Bishop JA, Marsh JL, Tilp S, Schnettler R, Simpson H, Alt V. Delayed union and nonunions: epidemiology, clinical issues, and financial aspects. Injury. 2014;45(Suppl 2):S3-S7.

24. Harrison WJ, Lewis CP, Lavy CB. Open fractures of the tibia in HIV positive patients: a prospective controlled single-blind study. Injury. 2004;35:852-856.

25. Heinze G, Schemper M. A solution to the problem of separation in logistic regression. Stat Med. 2002;21:2409-2419.

26. Heppenstall RB, Brighton CT, Esterhai JL Jr, Muller G. Prognostic factors in nonunion of the tibia: an evaluation of 185 cases treated with constant direct current. J Trauma. 1984;24:790-795.

27. Hernandez RK, Do TP, Critchlow CW, Dent RE, Jick SS. Patient-related risk factors for fracture-healing complications in the United Kingdom General Practice Research Database. Acta Orthop. 2012;83:653-660.

28. Kooistra BW, Dijkman BG, Busse JW, Sprague S, Schemitsch $\mathrm{EH}$, Bhandari $\mathrm{M}$. The radiographic union scale in tibial fractures: reliability and validity. J Orthop Trauma. 2010;24(Suppl 1):S81S86.

29. Lack WD, Starman JS, Seymour R, Bosse M, Karunakar M, Sims S, Kellam J. Any cortical bridging predicts healing of tibial shaft fractures. J Bone Joint Surg Am. 2014;96:1066-1072.

30. Metsemakers WJ, Handojo K, Reynders P, Sermon A, Vanderschot P, Nijs S. Individual risk factors for deep infection and compromised fracture healing after intramedullary nailing of tibial shaft fractures: a single centre experience of 480 patients. Injury. 2015;46:740-745.

31. Moghaddam A, Zimmermann G, Hammer K, Bruckner T, Grützner PA, von Recum J. Cigarette smoking influences the clinical and occupational outcome of patients with tibial shaft fractures. Injury. 2011;42:1435-1442.

32. Reverte MM, Dimitriou R, Kanakaris NK, Giannoudis PV. What is the effect of compartment syndrome and fasciotomies on fracture healing in tibial fractures? Injury. 2011;42:1402-1407.

33. Sanders DW, Bhandari M, Guyatt G, Heels-Ansdell D, Schemitsch EH, Swiontkowski M, Tornetta P III, Walter S; SPRINT Investigators. Critical-sized defect in the tibia: is it critical? results from the SPRINT Trial. J Orthop Trauma. 2014;28:632-635.

34. Sarmiento A, Sharpe FE, Ebramzadeh E, Normand P, Shankwiler J. Factors influencing the outcome of closed tibial fractures treated with functional bracing. Clin Orthop Relat Res.1995; 315:8-24.

35. Schemitsch EH, Bhandari M, Guyatt G, Sanders DW, Swiontkowski M, Tornetta P, Walter SD, Zdero R, Goslings JC, Teaque D, Jeray K, McKee MD; Study to Prospectively Evaluate Intramedullary Nails in Patients with Tibial Fractures (SPRINT) Investigators. Prognostic factors for predicting outcomes after intramedullary nailing of the tibia. J Bone Joint Surg Am. 2012;94: 1786-1793.

36. Scolaro JA, Schenker ML, Yannascoli S, Baldwin K, Mehta S, Ahn J. Cigarette smoking increases complications following fracture: a systematic review. J Bone Joint Surg Am. 2014;96:674-681.

37. Soni A, Tzafetta K, Knight S, Giannoudis PV. Gustilo IIIC fractures in the lower limb: our 15-year experience. J Bone Joint Surg Br. 2012;94:698-703.

38. Teitz CC, Carter DR, Frankel VH. Problems associated with tibial fractures with intact fibulae. J Bone Joint Surg Am. 1980;62:770-776

39. Thomas KA, Harris MB, Willis MC, Lu Y, MacEwen GD. The effects of the interosseous membrane and partial fibulectomy on loading of the tibia: a biomechanical study. Orthopedics. 1995;18: 373-383. 
40. Tytherleigh-Strong GM, Keating JF, Court-Brown CM. Extraarticular fractures of the proximal tibial diaphysis: their epidemiology, management and outcome. $J$ R Coll Surg Edinb. 1997;42:334-338.

41. Whelan DB, Bhandari M, Stephen D, Kreder H, McKee MD, Zdero R, Schemitsch EH. Development of the radiographic union score for tibial fractures for the assessment of tibial fracture healing after intramedullary fixation. J Trauma. 2010;68:629632.

42. Whorton AM, Henley MB. The role of fixation of the fibula in open fractures of the tibial shaft with fractures of the ipsilateral fibula: indications and outcomes. Orthopedics. 1998;21:1101-1105. 